I am not competent to discuss the chapters on time series. An important addition (relative to Dr Kendall's previous volumes) is an account of spectrum theory. A final chapter, recognizing the special difficulties in applying the theory of time series to "real" data, bricfly reviews special topics connected with estimation of parameters, testing the adequacy of a fitted model and multivariate series.

In reviewing a book of this magnitude, to pick out particular errors cr lapses in clarity is much easier than to evaluate fairly the features that are good but less specific. To say that the three volumes of Kendall and Stuart have weaknesses is in no way a denial of the great achievement they represent. For at least the next ten years, they will occupy a central place in statistical literature; for many years longer, they will be a standard reference. Will these authors, or any others, ever have the courage and skills to produce a new work on even grander scale in 1977 ?

D. J. FinNey

\section{ABSTRACT ALGEBRA}

\section{Abstract Algebra}

By Andrew O. Lindstrum, jun. (Holden-Day Series in Mathematics.) Pp. xii +211 . (San Francisco and London : Holden-Day, Inc., 1967.) $\$ 10$.

Most of the topics treated in this textbook of abstract algebra would find a place in courses for honours degrees in pure mathematics in this country at the present time. The author may have attempted to cover too many topics in the space available to him, for the treatment is sometimes rather compressed, particularly in group theory and linear algebra. Much care has been taken, however, in the preparation of the material and many points of detail have received thoughtful treatment.

While the substance of the book is good in many respects and $I$ have a feeling that the lectures on which the book is based were very successful, it does not in its present form seem to be an attractive exposition for an undergraduate reader. He would not read it with the pleasure he should get from such a course, and his interest might not be maintained. He might get used to the abstract and formal style and should make an effort to do so, but the practice of requiring the reader to supply his own proofs of various theorems is overdone. In moderation, the practice can stimulate and encourage a student, but here it might well irritate and depress. This defect of presentation is regrettable because the book has some interesting and commendable features.

The biblingraphy would have been more useful if it had been related in a more specific way with the various chapters of the book, and if some of the books mentioned were recommended for collateral reading and others for a study of further developments. H. O. Fotukes

\section{CLASSICAL ANALYSIS}

\section{A Second Course in Complex Analysis}

By William A. Veech. Pp. ix +246 . (New York and Amsterdam : W. A. Benjamin, Inc., 1967.) \$8.75.

VEECH builds on an assumed standard first course in complex variable, dealing with Cauchy's theorem, residues and simple mappings. $\mathrm{He}$ then pursues a number of related topics, all of which are now important parts of classical analysis. The style is midway between that of an elementary text and a research memoir, and should prepare the honours student for the reading of periodical literature.

The first four chapters hang very closely together, with a strong geometrical interest. A chapter on analytic continuation and one on conformal mappings, using the Schwarz lemma and reflexion principle, prepare for the chief theme, the relation between analytical and topological equivalence expressed most simply in the Riemann mapping theorem, here obtained as a corollary to the more general Koebe mapping theorem. In this domain, the language of covering surfaces and covering maps is conveniently employed. Following on this are the results springing from the Picard theorem that an integral function has at most one exceptional value, the Landau and Schottky theorems, Montel's normal families, the KoebeFaber distortion theorem, Bloch's constant. In this section, modular functions are used but the requisite properties are obtained in the text.

The remaining two chapters are a little detached from the chief theme. One deals with integral functions. deriving the Weierstrass product and the more difficult Hadamard product for functions of finite order. 'The last chapter discusses the Riemann zeta function and gives Ikehara's proof of the prime number theorem. In mentioning the way in which Landau, Wiener and Ikehara successively minimized the amount of zeta function theory required, the impetus given by the Tauberian theorems of Hardy and Littlewood is not noted.

\section{T. A. A. BrondBent}

\section{ELECTRIC MACHINES}

\section{Generalized Electric Machines}

By A. J. Ellison. Pp. 146. (London: George G. Harrap and Co., Ltd., 1967.) 20s. net.

\section{Electrical Machines}

(Electrical Engineering Series.) By A. Draper. Pp. xx+ 384. (London: Longmans, Green and Co., Ltd., 1967.) 63s. net.

DURING the past few years a large number of books have appeared dealing with electrical machines. Most of these have been concerned to try to present a "generalized" approach to the subject, beginning with a deseription of electro-mechanical transducers in either circuit or energy terms and often going some way towards considering the systems in which the transducers are employed.

Of the two books reviewed here, Ellison comes closer to the current fashion. It is a companion volume to the same author's book Electromechanical Energy Conversion. published in 1965; the present book, however, is unique in being wholly concerned with the structure and details of a laboratory course directed at complementing typical modern lecture coursos employing a generalized approach. The title, which is thus seen to be somewhat misleading as a description of the subject matter, presumably refers to the special purpose laboratory machines now widely available as vehicles for courses such as those described. The author has contributed much to the development of modern laboratory courses and, in this country, pioneered the first generalized laboratory machine in conjunction with AEI. Material sufficient for a course of up to twelve three hour periods is described, comprising for each experiment an introduction, a description of apparatus and general arrangements, a procedure, an outline of the relevant theory and calculations and a discussion and set of questions for the student. The course described is a good one, as would now, we believe, be generally agreed. But the fact that this agreement largely exists already. raises the question of exactly what need this text fulfils. Experienced teachers will have their own views on courseplanning, and will prepare laboratory sheets which will supersede this book as far as their students are concerned; but it could certainly be of value to younger and less experienced teachers and to those needing persuasion to make a change from a traditional to a generalized laboratory. 